\title{
Poly(Glycerol-Sebacate) Elastomer: A Mini Review
}

\author{
Atakan Tevlek ${ }^{1}$ and Halil Murat Aydin ${ }^{2 *}$ \\ ${ }^{1}$ Institute of Science and Engineering, Bioengineering Division, Hacettepe University, Turkey \\ ${ }^{2}$ Environmental Engineering Department \& Bioengineering Division and Centre for Bioengineering, Hacettepe University, Turkey \\ *Corresponding author: Halil Murat Aydin, Environmental Engineering Department \& Bioengineering Division and Centre for Bioengineering, \\ Hacettepe University, 06800, Ankara, Turkey
}

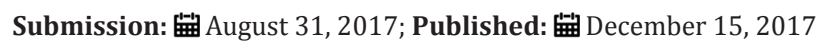

\begin{abstract}
Poly glycerol sebacate (PGS) is a synthetic polymer widely known in the field of tissue engineering and has achieved remarkable attention due to its desired properties such as having surface degradation and elastomeric behavior. Different synthesis methods based on pre-poly condensation step and crosslinking have been defined for PGS production till now. Thanks to its physico-chemical, mechanical, thermal and morphological properties; it has been proposed for numerous tissue engineering applications ranging from soft to hard tissue by researchers. Both in-vitro and in-vivo many research studies have been carried out not only upon PGS but also its composite forms. In addition, different production techniques and characterization methods have been pursued. Within the scope of this mini review article; the importance of PGS along with its discovery, production techniques, characterization and applications were described and explained.
\end{abstract}

\section{Introduction}

Regenerative medicine is an emerging field that uses different types of biomaterials consisting of polymers, ceramics, metals and their composites to restore or maintain the whole or partial tissues/organs. Some part of these materials mentioned above has potential to be used in clinical field owing to their superior properties, while another part needs further development. Both natural and synthetic polymeric materials are of enormous interest in the clinic due to their biocompatibility, mechanical properties, ECM like structures, degradation parallel to ECM formation etc.

Poly (glycerol-sebacate) (PGS) is a synthetic, biodegradable, thermo set and tough polymer first reported in 2002 by Wang et al. [1] and proposed for soft tissue engineering. It is emphasized in the first reported paper which introduces PGS to the scientific literature that it is cheap, bio-resorbable, bio degradable and has non-toxic degradation products [1]. Upon the discovery of PGS, many research studies in biomedical field had been launched by using this polymer including the development of polymer blends, composites, scaffold material for tissue engineering, adhesives, drug delivery system, sealants and coating materials [2]. PGS have mostly been proposed for soft tissue as a scaffold material. When the mechanical properties of soft tissues frequently studied in the context of tissue engineering are considered, Young Modulus values are observed between 0.1 and 11.1 MPa [3]. As for the mechanical properties of PGS recorded in the previous studies, it seems to be extremely compatible with soft tissues regarding to its tunable mechanical properties via cross linking [2,4]. Despite being suitable for soft tissue, we have also found examples in the literature for hard tissue repair, often combined with osteo conductive materials
[5-7]. Moreover, the combination of this material with $\beta$-tricalcium phosphate ceramics was proposed for guided bone regeneration in our previous study [8].

The main purpose of drug delivery studies is to distribute the drugs to a local target and sustain the therapeutic effects of drugs within the therapeutic frame and reduced toxicity [9]. Many damaged organs and tissues in the body can be accepted as a target. Therefore, drug delivery has a wide range of application area from anticancer therapy and contraceptive methods, to infectious disease [10]. In the field of drug delivery, the local distribution of target drugs/molecules is in close relationship with the degradation profile and the rate of the matrix. Studies conducted on the degradation of PGS have found that PGS degrades via surface erosion and it is understood that surface degradation is due to the breakage of the ester bonds [11]. PGS has been proposed as a matrix for anticancer drug encapsulations by Sun et al. [12]. In another study, berberine and chlorhexidine were encapsulated into the PGS as an active ingredient for periodontal regeneration by Deng et al. [13].

Yet another application of PGS includes their usage as tissue adhesives. There has been an increasing demand in the clinic for though biodegradable polymer adhesives that can cover the mechanical deformations while continuing to adhere to the tissue [14]. One of the possible reasons of demand can be disadvantages of conventional sutures and staples such as absence of elastic behavior and presence of toxicity or inflammatory effects. One of the other possible causes is that the elastic properties of conventional materials cannot adapt to every tissue [6]. Chen et al. 
[15] developed a synthetic tissue sealant from (PGS) and poly lactic acid (PLA) copolymer as an alternative to fibrin or collagen based adhesives to eliminate their viral risks. Mahdavi et al. [16] has proposed a new generation tissue adhesives made of poly (glycerolco-sebacate acrylate) to overcome the limitation of conventional materials due to adjustable elasticity through cross linking density.

Many biomaterial candidates have been combined with one another up to date to increase their mechanical or chemical properties or to cover their deficiencies. PGS is also one of these materials. PGS-fumarate and hydroxyapatite combination was proposed by Bodakhe et al. [17] to produce injectable, highly bioactive and biocompatible nano composites. The addition of hydroxyl apatite has been reported to increase ultimate strength of the structure. In another study, multi-walled carbon nanotube (MWCNT)/poly(glycerol-sebacate-citrate) (PGSC) elastomer composite was reported by Lui et al. [18]. The addition of carbon nanotubes was found to improve the strength and the modulus while degradation was reduced.

\section{Production and Characterization of PGS as a Biomaterial}

PGS is produced by combining glycerol and sebacic acid monomers with specific ratios. Hydroxyl groups of glycerol and carboxylic acids of sebacic acid undergo polycondensation reaction without any catalysts [19]. According to the first published article by Wang et al. [1] two step production protocols was needed to be followed: polycondensation and crosslinking. Equimolar mixtures of each starting monomers (1M of glycerol and sebacic acid) were reacted at $120^{\circ} \mathrm{C}$ under argon atmosphere for 24 hours before the pressure was reduced from 1 Torr to $40 \mathrm{~m}$ Torr. Consequently, the pre-polymer was exposed to $40 \mathrm{~m}$ Torrvacuum at $120^{\circ} \mathrm{C}$ for 48 hours for cross linking to occur [1]. A group of scientist investigated the alternative synthesis methods of PGS by changing molar ratio, curing temperature and cross linking parameters [15,20]. Also in our previous study, we demonstrated a facile PGS production method via microwave-assisted pre-polymerization without using a gas, catalyst or vacuum [21].

PGS, as a biomaterial, needs to be characterized to identify its possible application areas. For this purpose, physicochemical, mechanical and thermal properties of PGS together with its degradation and biocompatibility were investigated in detail [2]. PGS can be defined as transparent, almost odorless and colorless polyester. Wang et al. [1] characterized the chemical structure of PGS by FTIR analyses. The peaks differ in the spectra with respect to its crosslinking density, curing temperature and curing time [22]. According to the Nuclear Magnetic Resonance (NMR) spectroscopy analyses, the hydroxyl groups were bonded covalently to the carbon backbone, which provides hydrophilicity. Hydrogenbonding interactions between the hydroxyl groups, on the other hand, represents elasticity [1]. The hydrophilicity of the structure can be tunable by changing the crosslink parameters. As the curing time was increased, hydrophilicity was reduced due to the removal of hydroxyl groups from the structure [23].
The average Young modulus of PGS was calculated between 0.02 and $1.2 \mathrm{MPa}$ and ultimate tensile strength was found greater than $0.5 \mathrm{MPa}[4,20,24]$. The mechanical properties can be adjusted by changing the curing temperature, curing time and molar ratio of the monomers [25]. Thermal properties of PGS can be studied by Differential Scanning Calorimetry (DSC) analysis. Thermal properties of PGS depend on the transition temperature $\left(T_{g}\right)$ of the amorphous phase and melting temperature $\left(T_{m}\right)$ of the crystalline phase as it is a partially semi-crystalline polymer. As stated in the literature, PGS exhibits a $T_{g}$ at $-37^{\circ} \mathrm{C}$ with broad melting transition at temperature ranging from $-20^{\circ} \mathrm{C}$ to $40{ }^{\circ} \mathrm{C}$ according to the DSC diagram [26].

Crystallinity and morphology of PGS can be revealed by X-Ray Diffraction (XRD) analysis. PGS shows a broaden peak in the spectra. The main diffraction peak is centered at $19.8^{\circ} \mathrm{C}$ due to the doped sebacate in the structure. It was observed that the intensity of the diffraction peak decreased as the amount of sebacic acid in the structure increased. On the other hand once the curing time and temperature was increased, the crystallinity of PGS decreased $[22,27]$. The degradation mechanism of PGS can be defined as the surface degradation due to the cleavage of the ester bonds in the structures [11]. Wang et al. [1] noted on the first article on PGS that in-vitro and in-vivo degradation of PGS differs. In-vitro degradation of PGS was measured as $17.6 \%$ weight loss while it was completely absorbed in-vivo in a study that lasted 60 days. The degradation kinetics can be affected by production parameters such as curing time and temperature. For instance, if crosslink density increases in proportion with curing time or heat, the degradation kinetics decreases $[1,4]$.

Biocompatibility of PGS is one of its superior properties originated from its components: glycerol and sebacic acid approved by FDA [28]. Nevertheless, its biocompatibility was investigated by many researchers [29-31]. Although there is still no study emphasizing the toxicity of PGS, Chen et al. [32] reported that the local acidic environments encountered due to the hydrolysis of the ester groups releasing carboxylic acid [32]. Therefore, a number of surface functionalization methods have been suggested to enhance the cell migration, adhesion, differentiation and proliferation such as surface coating with a biomolecule, grafting of hydrophilic groups or enzyme treatment $[33,34,50]$.

\section{Biomedical Applications of PGS}

As summarized above, PGS has numerous advantages compared to other existing synthetic bio-degradable polymeric materials. Its elastic and biocompatible nature has attracted great attention of the researches who work in biomedical field. In the light of increasing demand on biomedical materials, researchers have been investigating the PGS in many different areas listed on Table 1.

\section{Conclusion}

PGS has a pivotal role in biomedical arena regarding to its elasticity, biocompatibility and biodegradability. Research studies are ongoing to develop PGS based material both alone and in 
combination with other materials in different forms and sizes. In addition to the technical specifications, providing a cheap, practical production method that does not require a lot of equipment will lead researchers to develop new biomaterials in the future.

Table 1: Biomedical application of PGS.

\begin{tabular}{|c|c|c|}
\hline Material & Application & Reference \\
\hline PGS & Cardiac Tissue Engineering & {$[4,35,36]$} \\
\hline PGS/Bioactive Glass & Bone Tissue Engineering & {$[5]$} \\
\hline PGS & Bone Tissue Engineering & [7] \\
\hline PGS/ $\beta$-TCP & Bone Tissue Engineering & {$[8,37]$} \\
\hline PGS & Drug Delivery & {$[12,13]$} \\
\hline PGS/PLA & $\begin{array}{c}\text { Surgical Sealants/Tissue } \\
\text { Adhesives }\end{array}$ & [15] \\
\hline PGS/Acrylate & $\begin{array}{c}\text { Surgical Sealants/Tissue } \\
\text { Adhesives }\end{array}$ & [16] \\
\hline PGS/Fumarate/HA & Bone Tissue Engineering & [17] \\
\hline PGS & Cartilage Tissue Engineering & [20] \\
\hline PGS & Shape Memory & [26] \\
\hline PGS & Nerve Tissue Engineering & [31] \\
\hline PGS & Soft Tissue Engineering & {$[38,39]$} \\
\hline PGS/PCL & Cardiac Tissue Engineering & [40] \\
\hline PGS/PBS-DLA & Cardiac Tissue Engineering & [41] \\
\hline PGS/E-PCL & Cornea Tissue Engineering & [42] \\
\hline PGS & Retina Tissue Engineering & [43] \\
\hline PGS/HA & Bone Tissue Engineering & [44] \\
\hline PGS/PMMA-Gelatin & Nerve Tissue Engineering & [45] \\
\hline PGS/Curcumin & Drug Delivery & [46] \\
\hline PGS & Coating Material & [47] \\
\hline Acr-PGS & 3D Printing & [48] \\
\hline $\begin{array}{l}\text { PGS/Urethane/ } \\
\text { Cellulose }\end{array}$ & Shape Memory & [49] \\
\hline
\end{tabular}

\section{References}

1. Wang Y, Ameer GA, Sheppard BJ, Langer R (2002) A tough biodegradable elastomer. Nature Biotechnology 20(6): 602-606.

2. Rai R, Tallawi M, Grigore A, Boccaccini AR (2012) Synthesis, properties and biomedical applications of poly(glycerol sebacate) (PGS): A review. Progress in Polymer Science 37(8): 1051-1078.

3. McKee CT, Last JA, Russell P, Murphy CJ (2011) Indentation versus tensile measurements of Young's modulus for soft biological tissues. Tissue engineering. Part B, Reviews 17(3): 155-164.

4. Chen QZ, Bismarck A, Hansen U, Junaid S, Tran MQ et al. (2008) Characterisation of a soft elastomer poly(glycerol sebacate) designed to match the mechanical properties of myocardial tissue. Biomaterials 29(1): 47-57.

5. Lin D, Yang K, Tang W, Liu Y, Yuan Y, et al. (2015) A poly(glycerol sebacate)coated mesoporous bioactive glass scaffold with adjustable mechanical strength, degradation rate, controlled-release and cell behavior for bone tissue engineering. Colloids Surf B Biointerfaces 131: 1-11.

6. Loh XJ, Abdul KA, Owh C (2015) Poly(glycerol sebacate) biomaterial: synthesis and biomedical applications. J Mater Chem B 3(39): 76417652 .

7. Zaky SH, Lee KW, Gao J, Jensen A, Verdelis K, et al. (2017) Poly (glycerol sebacate) elastomer supports bone regeneration by its mechanical properties being closer to osteoid tissue rather than to mature bone. Acta Biomater 54: 95-106.

8. Tevlek A, Hosseinian P, Ogutcu C, Turk M, Aydin HM (2017) Bi-layered constructs of poly(glycerol-sebacate)- $\beta$-tricalcium phosphate for bonesoft tissue interface applications. Materials Science and Engineering $\mathrm{C}$ 72(1): 316-324

9. Tiwari G, Tiwari R, Sriwastawa B, Bhati L, Pandey S, et al. (2012) Drug delivery systems: An updated review. Int J Pharm Investig 2(1): 2-11.

10. Martinho N, Damgé C, Reis CP (2011) Recent advances in drug delivery systems. Journal of Biomaterials and Nanobiotechnology 2011(2): 510526.

11. Pomerantseva I, Krebs N, Hart A, Neville CM, Huang AY, et al. (2009) Degradation behavior of poly(glycerol sebacate). Journal of Biomedical Materials Research Part A 91A(4): 1038-1047.

12. Sun ZJ, Chen C, Sun MZ, Ai CH, Lu XL, et al. (2009) The application of poly (glycerol-sebacate) as biodegradable drug carrier. Biomaterials 30(28): 5209-5214.

13. Yang B, Lv W, Deng Y (2017) Drug loaded poly(glycerol sebacate) as a local drug delivery system for the treatment of periodontal disease. RSC Adv 7(59): 37426-37435

14. Ryou M, Thompson CC (2006) Tissue adhesives: a review. techniques in gastrointestinal endoscopy. Techniques in Gastrointestinal Endoscopy 8(1): 33-37.

15. Chen QZ, Liang S, Thouas GA (2011) Synthesis and characterisation of poly(glycerol sebacate)-co-lactic acid as surgical sealants. Soft Matter 7(14): 6484-6492.

16. Mahdavi A, Ferreira L, Sundback C, Nichol JW, Chan EP, et al. (2008) A biodegradable and biocompatible gecko-inspired tissue adhesive. Proceedings of the National Academy of Sciences of the United States of America 105(7): 2307-2312.

17. Bodakhe S, Verma S, Garkhal K, Samal SK, Sharma SS, et al. (2013) Injectable photocrosslinkable nanocomposite based on poly(glycerol sebacate) fumarate and hydroxyapatite: development, biocompatibility and bone regeneration in a rat calvarial bone defect model. Nanomedicine (Lond) 8(11): 1777-1795.

18. Liu Q, Wu J, Tan T, Zhang L, Chen D, et al. (2009) Preparation, properties and cytotoxicity evaluation of a biodegradable polyester elastomer composite. Polymer Degradation and Stability 94(9): 1427-1435.

19. Liu Q, Tian M, Ding T, Shi R, Feng Y, et al. (2007) Preparation and characterization of a thermoplastic poly(glycerol sebacate) elastomer by two-step method. Journal of Applied Polymer Science 103(3): 14121419.

20. Kemppainen JM, Hollister SJ (2010) Tailoring the mechanical properties of 3D-designed poly(glycerol sebacate) scaffolds for cartilage applications. J Biomed Mater Res A 94(1): 9-18.

21. Aydin HM, Salimi K, Rzayev ZMO, Pișkin E (2013) Microwave-assisted rapid synthesis of poly(glycerol-sebacate) elastomers. Biomaterials Science 1(5): 503-509.

22. Jaafar IH, Ammar MM, Jedlicka SS, Pearson RA, Coulter JP (2010) Spectroscopic evaluation, thermal, and thermomechanical characterization of poly(glycerol-sebacate) with variations in curing temperatures and durations. Journal of Materials Science 45(9): 25252529 
23. Conejero GÁ, Gimeno HR, Sáez YM, Vilariño FG, Ortuño LI, et al. (2017) Correlating synthesis parameters with physicochemical properties of poly(glycerol sebacate). European Polymer Journal 87: 406-419.

24. Li X, Hong ATL, Naskar N, Chung HJ (2015) Criteria for quick and consistent synthesis of poly(glycerol sebacate) for tailored mechanical properties. Bio Macromolecules 16(5): 1525-1533.

25. Liu Q, Tian M, Shi R, Zhang L, Chen D, et al. (2007) Structure and properties of thermoplastic poly(glycerol sebacate) elastomers originating from prepolymers with different molecular weights. Journa of Applied Polymer Science 104(2): 1131-1137.

26. Cai W, Liu L (2008) Shape-memory effect of poly (glycerol-sebacate) elastomer. Materials Letters 62(14): 2175-2177.

27. Guo XL, Lu XL, Dong DL, Sun ZJ (2014) Characterization and optimization of glycerol/sebacate ratio in poly(glycerol-sebacate) elastomer for cell culture application. J Biomed Mater Res A 102(11): 3903-3907.

28. Grego AV, Mingrone G (1995) Dicarboxylic acids, an alternate fuel substrate in parenteral nutrition: an update. Clinical Nutrition 14(3): 143-148.

29. Li Y, Huang W, Cook WD, Chen Q (2013) A comparative study on poly(xylitol sebacate) and poly(glycerol sebacate): mechanical properties, biodegradation and cytocompatibility. Biomed Mater 8(3): 035006.

30. Gao J, Ensley AE, Nerem RM, Wang Y (2007) Poly(glycerol sebacate) supports the proliferation and phenotypic protein expression of primary baboon vascular cells. J Biomed Mater Res A 83(4): 1070-1075.

31. Sundback CA, Shyu JY, Wang Y, Faquin WC, Langer RS, et al. (2005) Biocompatibility analysis of poly(glycerol sebacate) as a nerve guide material. Biomaterials 26(27): 5454-5464.

32. Chen Q Jin L, Cook WD, Mohn D, Lagerqvist EL, et al. (2010) Elastomeric nanocomposites as cell delivery vehicles and cardiac support devices. Soft Matter 6(19): 4715-4726.

33. Sales VL, Engelmayr GC, Johnson JA, Gao J, Wang Y, et al. (2007) Protein precoating of elastomeric tissue-engineering scaffolds increased cellularity, enhanced extracellular matrix protein production, and differentially regulated the phenotypes of circulating endothelial progenitor cells. Circulation 116(11 Suppl1): 155-163.

34. Rai R, Keshavarz T, Roether JA, Boccaccini AR, Roy I (2011) Medium chain length polyhydroxy alkanoates, promising new biomedical materials for the future. Materials Science and Engineering R: Reports 72(3): 29-47.

35. Masoumi N, Jean A, Zugates JT, Johnson KL, Engelmayr GC (2013) Laser microfabricated poly(glycerol sebacate) scaffolds for heart valve tissue engineering. J Biomed Mater Res A 101(1): 104-114.

36. Rai R, Tallawi M, Barbani N, Frati C, Madeddu D, et al. (2013) Biomimetic poly(glycerol sebacate) (PGS) membranes for cardiac patch application. Mater Sci Eng C Mater Biol Appl 33(7): 3677-3687.

37. Yang K, Zhang J, Ma X, Ma Y, Kan C, et al. (2015) $\beta$-Tricalcium phosphate/ poly(glycerol sebacate) scaffolds with robust mechanical property for bone tissue engineering. Mater Sci Eng C Mater Biol Appl 56: 37-47.

38. Mitsak AG, Dunn AM, Hollister SJ (2012) Mechanical characterization and non-linear elastic modeling of poly(glycerol sebacate) for soft tissue engineering. Journal of the Mechanical Behavior of Biomedical Materials 11: 3-15.

39. Zhang, X, Jia C, Qiao X, Liu T, Sun K (2016) Porous poly(glycerol sebacate) (PGS) elastomer scaffolds for skin tissue engineering. Polymer Testing 54: 118-125.

40. Rai R, Tallawi M, Frati C, Falco A, Gervasi A, et al. (2015) Bioactive Electrospun Fibers of Poly(glycerol sebacate) and Poly(e-caprolactone) for Cardiac Patch Application. Advanced Healthcare Materials 4(13): 2012-2025

41. Tallawi M, Zebrowski DC, Rai R, Roether JA, Schubert DW, et al. (2015) Poly(Glycerol Sebacate)/Poly(Butylene Succinate-Butylene Dilinoleate) Fibrous Scaffolds for Cardiac Tissue Engineering. Tissue Eng Part C Methods 21(6): 585-596.

42. Salehi S, Czugala M, Stafiej P, Fathi M, Bahners T, et al. (2017) Poly (glycerol sebacate)-poly ( $\varepsilon$-caprolactone) blend nanofibrous scaffold as intrinsic bio-and immunocompatible system for corneal repair. Acta Biomater 50: 370-380.

43. Redenti S, Neeley WL, Rompani S, Saigal S, Yang J, et al. (2009) Engineering retinal progenitor cell and scrollable poly(glycerolsebacate) composites for expansion and subretinal transplantation. Biomaterials, 30(20): 3405-3414.

44.Zaky SH, Lee K, Gao J, Jensen A, Close J, et al. (2014) Poly (Glycerol sebacate) elastomer: a novel material for mechanically loaded bone regeneration. Tissue Eng Part A 20(1-2): 45-53.

45. Hu J, Kai D, Ye H, Tian L, Ding X, et al. (2017) Electrospinning of poly(glycerol sebacate)-based nanofibers for nerve tissue engineering. Mater Sci Eng C Mater Biol Appl 70(Pt 2): 1089-1094.

46. Sun ZJ, Sun B, Tao RB, Xie X, Lu XL, et al. (2013) A poly(glycerol-sebacatecurcumin) polymer with potential use for brain gliomas. J Biomed Mater Res Part A 101A(1): 253-260.

47. Kim MJ, Hwang MY, Kim J, Chung DJ (2014) Biodegradable and elastomeric poly(glycerol sebacate) as a coating material for nitinol bare stent. BioMed Research International 2014(2014): 1-7.

48. Yeh YC, Highley CB, Ouyang L, Burdick JA (2016) 3D printing of photocurable poly(glycerol sebacate) elastomers. Biofabrication 8(4): 45004.

49. Wu T, Frydrych M, O’Kelly K, Chen B (2014) Poly(glycerol sebacate urethane)-cellulose nanocomposites with water-active shape-memory effects. Biomacromolecules 15(7): 2663-2671

50. Frydrych M, Román S, Macneil S, Chen B (2015) Biomimetic poly(glycerol sebacate)/poly(l-lactic acid) blend scaffolds for adipose tissue engineering. Acta Biomater 18: 40-49. 